ARTÍCULO ORIGINAL

\title{
Propuesta de una dosis de marbofloxacina para el tratamiento de infecciones asociadas a Escherichia coli en cabras de tres semanas de vida
}

\author{
Dell'Elce $A^{1}$, Menseguez $S^{1}$, Castromán $R^{1}$, Anadón $A^{1}$, Ferrer $A^{1}$, López $A^{1}$, Ruiz $N^{1}$, Botto $M^{2}$, \\ Candioti $\mathrm{V}^{3}$, Formentini $\mathrm{E}^{1, *}$ \\ ${ }^{1}$ Laboratorio de Farmacología y Toxicología, Facultad de Ciencias Veterinarias, Universidad \\ Nacional del Litoral (FCV-UNL), Argentina. \\ ${ }^{2}$ Cátedra de Bioestadística, FCV-UNL, Argentina. \\ ${ }^{3}$ Cátedra de Semiología, FCV-UNL, Argentina. \\ * Correspondencia: Enrique Formentini, FCV-UNL, R.P. Kreder 2805, 3080 \\ Esperanza, Santa Fe, Argentina. \\ E-mail: eforment@fcv.unl.edu.ar
}

RESUMEN. Se estimó una dosis de marbofloxacina (MFX) para tratar infecciones gastrointestinales asociadas a Escherichia coli en cabras de tres semanas de vida. La farmacodinamia de MFX sobre $E$. coli se evaluó in vitro estimando las concentraciones inhibitoria mínima (CIM), bactericida mínima (CBM) y preventiva de mutantes (CPM). Marbofloxacina se administró en cabras de tres semanas de edad por vía subcutánea a una dosis de $2 \mathrm{mg} / \mathrm{kg}$. Los parámetros farmacocinéticos se estimaron mediante análisis no compartimental. La dosis de MFX capaz de proteger al 95\% de una población se calculó considerando la distribución poblacional de los parámetros farmacocinéticos. La eficacia de MFX se evaluó con la relación entre el área bajo la curva y la CPM (ABC/CPM) con un valor de corte de $22 \mathrm{~h}$. Los resultados mostraron que la dosis estimada de MFX para alcanzar la remisión clínica de infecciones gastrointestinales causadas por E. coli y prevenir la emergencia de cepas resistentes en el $95 \%$ de una población de cabras de tres semanas de vida fue de $3,179 \mathrm{mg} / \mathrm{kg}$, que a los fines prácticos se fijó en $3,5 \mathrm{mg} / \mathrm{kg}$.

SUMMARY. Proposal of a marbofloxacin dose to treat infections associated to Escherichia coli in 3-week-old goats. A dose of marbofloxacin (MFX) to treat gastrointestinal infections caused by Escherichia coli in 3-week-old goats was estimated. The pharmacodynamics of MFX against $E$. coli was evaluated in vitro by estimation of mínimum inhibitory concentration (MIC), mínimum bactericide concentration (MBC) and mutant prevention concentration (MPC). Marbofloxacin was administered to 3-week -old goats by subcutaneous route at the dose of $2 \mathrm{mg} / \mathrm{kg}$. The pharmacokinetic parameters were estimated by non-compartmental analysis. The dose of MFX capable to protect the $95 \%$ of population was calculated considering the population distribution of pharmacokinetic parameters. The efficacy of MFX was evaluated by the relationship between the area under curve and MPC (AUC/MPC) with a cut-off value of $22 \mathrm{~h}$. The results showed that the estimated dose of MFX to reach the clinical outcome of gastrointestinal infections caused by $E$. coli and to prevent the bacterial resistance at the $95 \%$ of the population of 3-week-old goats was $3.179 \mathrm{mg} / \mathrm{kg}$, which for practical reasons was fixed at $3.5 \mathrm{mg} / \mathrm{kg}$.

Palabras clave: marbofloxacina, Escherichia coli, cabras

Keywords: marbofloxacin, Escherichia coli, goats

\section{Introducción}

La resistencia de las bacterias a los antibióticos (ATBs) es una problemática que se ha incrementado considerablemente en los últimos años. Este fenómeno se origina por la plasticidad con que las bacterias desarroIlan mecanismos que evitan el efecto bactericida o bacteriostático de los ATBs. Si bien es de común consenso que la dosificación de un ATB es la clave para eliminar las bacterias del sitio de infección, al cumplirse 90 años del descubrimiento de la penicilina (1928) aún se sigue discutiendo acerca de cuál debería ser el esquema terapéutico que garantice la remisión clínica y la cura bacteriológica. Sin embargo hoy se acepta que un tratamiento antibiótico además de lograr la remisión clínica también debe reducir la emergencia de cepas bacterianas resistentes (Burgess, 1999). En este sentido, la integración farmacocinética-farmacodinámica (PK- 
PD) permite establecer la relación entre el ATB y la bacteria, cuantificar la potencia y eficacia de este y diseñar estrategias de dosificación para prevenir la emergencia de resistencia (Drusano, 2007; Nielsen y Friberg, 2013).

Marbofloxacina (MFX) es una fluoroquinolona (FQ) sintética de tercera generación desarrollada exclusivamente para ser usada en medicina veterinaria (EMEA, 1996). Es efectiva sobre la mayoría de las bacterias gramnegativas, y Mycoplasma (Haritova et al. 2006; Vallé et al. 2012; Tohamy y El-Gendy, 2013). La farmacocinética de MFX ha sido estudiada en diferentes especies de animales, incluyendo caninos, porcinos, bovinos, bubalinos y caprinos, mostrando que logra elevadas concentraciones plasmáticas y una rápida y extensa distribución tisular, lo que determina que sus concentraciones en tejidos tales como pulmón, hígado y riñón sean mayores a las observadas en plasma, al tiempo que presenta una elevada biodisponibilidad (F) con valores cercanos al 100\% (Waxman et al. 2001; Schneider et al. 2004; Albarellos et al. 2005; Ding et al. 2010; Sidhu et al. 2010; Lei et al. 2017). En animales de laboratorio y cerdos su unión a proteínas plasmáticas es débil $(<10 \%)$, aunque en bovinos su unión es cercana al 30\% (EMEA, 1999). Las características farmacocinéticas de MFX la hacen un antimicrobiano atractivo para tratar infecciones serias en animales de producción tales como septicemias y gastroenteritis causadas por bacterias aerobias grampositivas y gramnegativas (El Garch et al. 2017).

Marbofloxacina presenta actividad dependiente de la concentración con prolongado efecto posantibiótico (Canut Blasco et al. 2015), aunque algunos autores afirman que su eficacia también es codependiente del tiempo de exposición (Blot et al. 2014). Se acepta que la posología de las FQs que garantiza la cura clínica para infecciones no graves y las causadas por bacterias grampositivas es la que logra una relación entre el área bajo la curva y la concentración inhibitoria mínima (ABC / $\mathrm{CIM}) \geq 25-50 \mathrm{~h}$. En el caso de infecciones graves y las causadas por bacterias gramnegativas, esta relación debe presentar un valor $\geq 125 \mathrm{~h}$ (Drusano, 2007; Blondeau, 2009; Barbour et al. 2010; Canut Blasco et al. 2015).

La capacidad de las bacterias para generar resistencia a las FQs mediante mutaciones de un solo paso (Blondeau, 2009), ha cambiado el escenario de los índices de eficacia PK/PD, donde la CIM era el parámetro farmacodinámico de referencia para el cálculo de la dosis de estos ATBs. En los últimos años ha entrado en vigencia la concentración preventiva de mutantes (CPM), que es la mínima concentración de un ATB que inhibe el desarrollo de mutantes de primer paso (Dong et al. 1999).

En este nuevo escenario, la CPM ha comenzado a utilizarse en el diseño de los regímenes terapéuticos de las FQs (Ahmad et al. 2016). Investigaciones realizadas por Olofsson et al. (2006) acerca de la selección de resistencia de cepas de Escherichia coli (E. coli) a la acción de FQs (enrofloxacina) han mostrado que una relación $A B C / C P M \geq 22 \mathrm{~h}$ es eficaz para prevenir la selección de mutantes resistentes de esta bacteria. Dentro de este contexto, el tiempo de exposición a concentraciones mayores a la CPM ( $\mathrm{t}>\mathrm{CPM}$ ) también es considerado como una información importante a tener en cuenta en el diseño de los regímenes terapéuticos de las FQs (Xu et al. 2013).

En Argentina el caprino es una especie productiva menor, cuya explotación genera productos lácteos, carne y cuero. En general, esta se realiza en regiones agroecológicas áridas que no permiten generar otra actividad económica rentable. La explotación del ganado caprino generalmente es practicada por pequeños productores de bajo nivel educativo, quienes la utilizan principalmente para autoconsumo a manera de otorgar sustento económico a sus familias, las que se desenvuelven en un marco de alta vulnerabilidad.

Dentro de este contexto las condiciones alimenticias, higiénico sanitarias y la casi ausencia de asistencia y asesoramiento veterinario, condicionan la emergencia de enfermedades parasitarias, víricas y bacterianas. En las primeras semanas de vida de los cabritos, la falta de higiene, la falta de desinfección del cordón umbilical, el hacinamiento, el calor y la humedad excesiva predisponen la emergencia de la diarrea blanca o colibacilosis causada por la bacteria E. coli sola o asociada a virus. En estos casos la materia fecal es por lo general blanca amarillenta de consistencia cremoso a casi líquida y los cabritos se deshidratan rápidamente. Los porcentajes de mortandad pueden ser altos si no se tratan adecuadamente (Bedotti y Rossanigo, 2011; de la Rosa Carbajal, 2013), siendo los tratamientos realizados en forma empírica por los mismos productores sin asesoramiento veterinario (Rossanigo, 2013).

En Argentina, casi la totalidad de los medicamentos de uso veterinario no están indicados para ser utilizados en cabras así como en otras especies productivas menores, de manera que éstas permanecen huérfanas de terapéutica, por lo que el empleo de los medicamentos en esta especie se realiza fuera de rótulo. En el caso de MFX, ésta se utiliza en cabras a la dosis de $2 \mathrm{mg} / \mathrm{kg}$ (Waxman et al. 2001; Waxman et al. 2004; Aliabadi y Lees, 2002; Sidhu et al. 2010) que es la recomendada para la especie bovina, administrando una dosis diaria durante 3-5 días consecutivos. La propuesta de una dosis de MFX para cabras de tres semanas de vida para el tratamiento de infecciones gastrointestinales asociadas a $E$. coli, plantea para el investigador un desafío en la realización de los ensayos clínicos in vivo, en los que el empleo de animales experimentales debe restringirse solo a situaciones en las que no existen alternativas para reemplazar a los mismos y en esos casos el investigador debe garantizar que los animales sean sometidos a un mínimo de estrés y sufrimiento. Esta situación hace que en el área de la investigación farma- 
cológica tomen relevancia alternativas experimentales como los estudios in vitro e in silico (Yu y Wilson, 2010).

Con estudios in vitro se determina la actividad y la eficacia de un ATB frente a la cepa bacteriana determinada, reemplazando así los ensayos in vivo sobre animales experimentales infectados. Por último, los estudios in silico consisten en analizar e integrar la información generada en los ensayos in vivo e in vitro mediante empleo de programas informáticos específicos. En nuestro caso, mediante modelos matemáticos, se establecen las relaciones entre las concentraciones del ATB en el organismo y su efecto antibacteriano. Los tres tipos de ensayos se complementan para cumplir con el principio de las tres $R$ que exige la ciencia biomédica: (i) reducir el número de animales en los estudios experimentales in vivo; (ii) refinar las técnicas y metodologías in vivo e in vitro para obtener resultados más confiables y (iii); reemplazar el modelo in vivo tanto como sea posible (Fina et al. 2013).

Para el cumplimiento de las tres $R$, emerge el metaanálisis como una herramienta de resumen de múltiples estudios relacionados con un tema específico, operando como nexo entre la producción y difusión del conocimiento (publicaciones) y la aplicabilidad de estos conocimientos (Gimenez, 2012). El meta-análisis permite: (i) evaluar la información reportada por otros investigadores y utilizarla en un estudio de investigación farmacológica; (ii) evitar la realización estudios in vivo e in vitro ya hechos; (iii) reducir el número de animales experimentales en un ensayo in vivo y (iiii) maximizar el empleo de los recursos disponibles. En base a lo expuesto, es evidente que la problemática de la diarrea neonatal en cabras de joven edad de etiología bacteriana (colibacilosis) no es simple y abarca aspectos académicos, farmacológicos, productivos y sociales. Por lo tanto, el objetivo de este trabajo fue: (i) estudiar in vitro la actividad de MFX sobre $E$. coli determinando la CIM y la CPM de la cepa bacteriana en estudio; (ii) estudiar in vivo la cinética de disposición plasmática de MFX en cabras de tres semanas de edad y (iii) estimar in sílico por integración PK/PD la dosis óptima de MFX en cabras de tres semanas de edad para el tratamiento de infecciones gastrointestinales asociadas a $E$. coli y evitar la emergencia de resistencia bacteriana.

\section{Materiales y métodos}

Para la realización de los ensayos in vitro se utilizó un estándar de MFX con un $99,7 \%$ de pureza proporcionado por Laboratorio Allignani Hnos. SRL. Al no disponer en Argentina de una especialidad farmacéutica inyectable de MFX para uso en grandes animales, el estudio farmacocinético se realizó utilizando una solución inyectable experimental al $10 \% \mathrm{p} / \mathrm{v}$ fabricada por Laboratorio Allignani Hnos. SRL. Como bacteria se utilizó la cepa estandarizada de E. coli (ATCC 25922) como testigo de la sensibilidad de las cepas autóctonas a MFX y por carecer esta de mecanismos de resistencia (EMA, 2016).
Se trabajó con dos tipos de inóculos bacterianos: (i) inóculos de densidad estándar e (ii) inóculos de densidad elevada. Los inóculos de densidad estándar se prepararon a partir de colonias de E. coli (ATCC 25922) incubadas durante $24 \mathrm{~h}$ sobre placas de agar MacConkey. Posteriormente los microorganismos fueron suspendidos en solución isotónica estéril hasta lograr una concentración final aproximada de $5 \times 10^{5}$ unidades formadoras de colonia/mL (ufc/mL) (García Rodríguez et al. 2001). Los inóculos de densidad elevada se construyeron según el procedimiento descripto por Blondeau (2009), logrando una concentración final $>1 x$ $10^{10} \mathrm{ufc} / \mathrm{mL}$. La concentración final de los inóculos de densidad estándar y elevada fue corroborada por recuento de ufc/placa.

El valor de la CIM de MFX sobre E. coli (ATCC 25922) se determinó mediante el test de macrodilución en tubo en caldo Mueller Hinton sobre inóculos de concentración estándar (CLSI, 2008), dentro de un intervalo de concentraciones comprendido entre 0,0078 y $1 \mu \mathrm{g} / \mathrm{mL}$ y se estimó como la menor concentración de MFX que inhibió el crecimiento visible de bacterias. De los tubos en los que no se observó desarrollo bacteriano visible se tomaron alícuotas de $100 \mu \mathrm{L}$ que se extendieron sobre placas de agar MacConkey y que se incubaron a $35^{\circ} \mathrm{C}$ durante $24 \mathrm{~h}$, luego de lo cual se procedió al conteo de las ufc/placa. La concentración bactericida mínima (CBM) y la concentración de erradicación bacteriana mínima (CEBM) se determinaron como las concentraciones de MFX que lograron una reducción del $99,90 \%$ y $99,99 \%$ del conteo bacteriano inicial respectivamente (Patricelli et al. 2017).

Las curvas de crecimiento y muerte bacteriana se realizaron en caldo Mueller Hinton sobre 8 inóculos de densidad estándar. El primero fue utilizado como testigo del crecimiento de E. coli (ATCC 25922) en ausencia de MFX. Los inóculos restantes fueron enfrentados a concentraciones de MFX equivalentes a 0,25 0,5 - 1 - 2 - 4 - 8 y 32 x CIM. Todos los inóculos fueron incubados a $35^{\circ} \mathrm{C}$ durante $24 \mathrm{~h}$, extrayendo de los mismos alícuotas de $100 \mu \mathrm{L}$ a las $0-1-2-3,5-10$ y $24 h$.

Con cada una de esas alícuotas se realizaron diluciones seriadas en solución fisiológica estéril y $100 \mu \mathrm{L}$ de cada dilución final fueron extendidos sobre la superficie de placas de agar MacConkey, las que se incubaron en estufa a $35^{\circ} \mathrm{C}$ durante $24 \mathrm{~h}$, luego de lo cual se procedió al conteo de las ufc/placa (Blondeau, 2009). El número de las ufc/mL de cada tiempo de muestreo se determinó multiplicando el número de ufc/placa por el factor derivado de las diluciones de cada muestra, siendo el límite de detección de $10 \mathrm{ufc} / \mathrm{mL}$.

A fin de facilitar la representación gráfica y la interpretación de las curvas de crecimiento y muerte, el conteo bacteriano en cada tiempo de muestro se expresó como $\log _{10} \mathrm{ufc} / \mathrm{mL}$. 
Para evaluar la actividad de las concentraciones de MFX sobre $E$. coli (ATCC 25922), se utilizaron tres criterios de eficacia: (i) actividad bacteriostática; (ii) actividad bactericida y (iii) actividad de erradicación bacteriana (Sidhu et al. 2010).

(i) La actividad bacteriostática fue definida como la ausencia de eficacia, es decir cuando la diferencia entre el $\log _{10}$ del conteo bacteriano a las $24 \mathrm{~h}\left(\log _{10}\right.$ $\left.\mathrm{N}_{24}\right)$ y el $\log _{10}$ del conteo bacteriano inicial $\left(\log _{10} \mathrm{~N}_{0}\right)$ fue cero $\left(\log _{10} N_{24}-\log _{10} N_{0}=0\right)$.

(ii) La actividad bactericida fue definida como una reducción igual o mayor a $3 \log _{10}$ respecto del valor del $\log _{10} \mathrm{~N}_{0}\left(\log _{10} \mathrm{~N}_{24}-\log _{10} \mathrm{~N}_{0} \geq-3\right)$. Este valor corresponde a una reducción del 99,9\% del número inicial de bacterias viables y se correlaciona con una reducción de la carga bacteriana suficiente para lograr la remisión del cuadro clínico.

(iii) La actividad de erradicación bacteriana fue definida como una reducción igual o mayor a $4 \log _{10}$ respecto del valor de $\log _{10} N_{0}\left(\log _{10} N_{24}-\log _{10} N_{0} \geq-4\right)$. Este valor corresponde a una reducción del $99,99 \%$ del número de inicial bacterias viables y se correlaciona con una reducción de carga bacteriana suficiente para permitir la erradicación de las mismas por acción de la respuesta inmune del hospedador, lo que equivaldría a la cura bacteriológica.

La eficacia in vitro de concentraciones crecientes de MFX sobre E. coli (ATCC 25922) expresada como $\log _{10}$ $\mathrm{N}_{24}-\log _{10} \mathrm{~N}_{0}$, fue ajustada con el modelo sigmoideo de respuesta máxima o de Hill (Goutelle et al. 2008) que se presenta en la ecuación 1.

$$
E=E_{0}+\frac{E_{\max } \cdot C^{\propto}}{C E_{50}^{\alpha}+C^{\propto}}
$$

Ecuación 1

Donde $\mathrm{E}$ es el efecto de una concentración determinada de MFX expresado como la diferencia entre $\log _{10} N_{24}$. $\log _{10} N_{0}$, $E_{0}$ es el $\log _{10} N_{0}, E_{\max }$ es el efecto máximo estimado, $\mathrm{CE}_{50}$ es la concentración de MFX que logra el $50 \%$ de $E_{\max } y \alpha$ es el coeficiente de sigmoidicidad. El ajuste de los datos experimentales se realizó por regresión no lineal ponderada de mínimos cuadrados con el software ADAPT II (BMSR, University of Southern California). Las concentraciones estimadas de MFX necesarias para obtener los siguientes efectos; 0 (bacteriostático o CIM), $-3 \log _{10}$ (bactericida o CBM) y $-4 \log _{10}$ (erradicación bacteriana o CEMB) se calcularon a partir de los parámetros estimados por el modelo sigmoideo de respuesta máxima, reordenando la ecuación 1 tal como se presenta a continuación en la ecuación 2 .

$$
C=\left[\frac{\left(E-E_{0}\right) \cdot C E_{50}^{\alpha}}{E_{\max }+E_{0}-E}\right]^{\frac{1}{\alpha}}
$$

Ecuación 2
Donde $C$ es la concentración de MFX necesaria para obtener un efecto antibacteriano determinado. El resto de los símbolos fueron explicados al pie de la ecuación 1. La determinación de la CPM de MFX sobre E. coli (ATCC 25922) se realizó según el procedimiento de inhibición de desarrollo en placa descripto por Blondeau (2009). Brevemente, se prepararon placas de agar MacConkey conteniendo concentraciones de MFX equivalentes a 0 - 1 - 4 - 14 - 24 - 34 - 44 - 54 y 64 x CIM. Cada serie de concentraciones se preparó por cuadruplicado. Sobre la superficie de cada una de las placas se extendieron $100 \mu \mathrm{L}$ de un inóculo de densidad elevada $\left(>1 \times 10^{10} \mathrm{ufc} / \mathrm{mL}\right.$ ). Todas las placas se incubaron a $35^{\circ} \mathrm{C}$ durante $48 \mathrm{~h}$. La CPM se determinó como la mayor concentración de MFX que inhibió el desarrollo de colonias bacterianas sobre la superficie de las placas de agar.

El estudio farmacocinético de MFX fue realizado en las instalaciones de la Unidad Académico Productiva de la Facultad de Ciencias Veterinarias de la UNL, contando con la aprobación del Comité de Ética Institucional (CEI) de la misma unidad académica. Se utilizaron seis cabras de raza Boer de tres semanas de edad (3 machos y 3 hembras), sanas y con pesos comprendidos entre $7,5 \mathrm{y}$ $7,85 \mathrm{~kg}$ a las que se les administró por vía SC en la región de la tabla del cuello una dosis de $2 \mathrm{mg} / \mathrm{kg}$ de la formulación experimental de MFX al $10 \% \mathrm{p} / \mathrm{v}$.

A cada animal se le realizaron extracciones de sangre de la vena yugular, antes (tiempo 0) y a los siguientes tiempos posadministración: 30 min y $1-1,5-3-5$ - 8 - 11 y $24 \mathrm{~h}$, colectando las muestras de sangre en tubos de polipropileno heparinizados. Posteriormente las muestras de sangre fueron centrifugadas a $1300 \mathrm{~g}$ durante 10 min a $4^{\circ} \mathrm{C}$ y el plasma sobrenadante se distribuyó en crioviales que fueron almacenados a $-20^{\circ} \mathrm{C}$ hasta su posterior análisis.

La cuantificación de MFX se realizó mediante el método microbiológico en placa descripto por Tohamy y ElGendy (2013), utilizando E. coli (ATCC 25922) como microorganismo test. Brevemente, a partir de un cultivo de E. coli (ATCC 25922) de 24 h se realizó una suspensión bacteriana en solución fisiológica con una densidad aproximada de $1,5 \times 10^{8} \mathrm{ufc} / \mathrm{mL}$. Posteriormente se agregó $0,1 \mathrm{~mL}$ de la suspensión bacteriana cada $100 \mathrm{~mL}$ de Agar Antibiótico $\mathrm{n}^{\circ} 1$ a $45-55^{\circ} \mathrm{C}$. Veinticinco $\mathrm{mL}$ de agar inoculado se vertieron en placas de petri de $90 \mathrm{~mm}$ de diámetro logrando un espesor de 6 $\mathrm{mm}$. Sobre la superficie de las placas se depositaron en disposición radial seis cilindros de acero inoxidable de 8 $\mathrm{mm}$ de diámetro por $8 \mathrm{~mm}$ de altura. Las curvas de calibración se construyeron con plasma de cabras de tres semanas de vida libre de antibiótico, enriqueciendo el mismo con el estándar de MFX hasta lograr concentraciones de $0,0156-0,0625-0,25-0,75$ y $2 \mu \mathrm{g} / \mathrm{mL}$. Los cilindros fueron llenados con $100 \mu \mathrm{L}$ de las muestras de plasma test o el plasma enriquecido con el estándar de MFX. Las placas fueron incubadas a $35^{\circ} \mathrm{C}$ durante $24 \mathrm{~h}$ y se midieron los diámetros de la zona de inhibición. Las concentraciones de MFX en las muestras de plasma test 
fueron calculadas a partir de las curvas de calibración. La gráfica semilogarítmica de los diámetros de inhibición en función de las concentraciones del estándar de MFX mostró linealidad entre las concentraciones comprendidas entre 0,0156 y $2 \mu \mathrm{g} / \mathrm{mL}$, siendo el coeficiente de correlación de Pearson de 0,9992. El límite de cuantificación de MFX fue fijado en $0,0156 \mu \mathrm{g} / \mathrm{mL}$ y el valor del coeficiente de variación estimado para la concentraciones bajas $(0,0156 \mu \mathrm{g} / \mathrm{mL})$, medias $(0,25 \mu \mathrm{g} / \mathrm{mL})$ y altas $(0,2 \mu \mathrm{g} / \mathrm{mL})$ fue de $3,2 \%, 4,1 \%$ y $4,5 \%$ respectivamente.

El análisis farmacocinético de los seis perfiles de concentración plasmática de MFX se realizó mediante el método no compartimental, utilizando el programa informático PKSolver (Zhang et al. 2010). El perfil de concentraciones plasmáticas promedio se analizó con un modelo de un compartimiento con absorción y eliminación de orden uno, donde los datos de concentración plasmática fueron ajustados mediante regresión no lineal ponderada de mínimos cuadrados. El modelo farmacocinético mono compartimental se describe con la ecuación propuesta por Bateman (1910) que se presenta a continuación.

$$
C_{p}=\frac{D \cdot F \cdot k_{a}}{V_{d} \cdot\left(k_{a}-k_{e}\right)} \cdot e^{-k_{e} \cdot t}-e^{k_{a} \cdot t}
$$

Ecuación 3

Donde $C_{p}$ es la concentración plasmática a un tiempo determinado; $D$ es la dosis, $V_{d}$ es el volumen de distribución aparente, $\mathrm{F}$ es la fracción biodisponible, $\mathrm{k}_{\mathrm{a}}$ y $\mathrm{k}_{\mathrm{e}}$ son las constantes de primer orden aparente de absorción y eliminación respectivamente y t es el tiempo. Sin embargo al no disponer del valor de $\mathrm{F}$, la ecuación fue reordenada tal como se presenta en la ecuación 4.

$$
C_{p}=\frac{D \cdot k_{a}}{V_{d} / F \cdot\left(k_{a}-k_{e}\right)} \cdot e^{-k_{e} \cdot t}-e^{-k_{a} \cdot t}
$$

Ecuación 4

Donde $V_{d} / F$ es el volumen de distribución aparente sobre la fracción biodisponible. El resto de los símbolos ya fueron explicados. Al no haberse realizado la administración intravascular de MFX, no se pudo estimar el valor real de $\mathrm{F}$, por lo que se utilizó la herramienta del meta-análisis para calcular la fracción biodisponible teórica $\left(F_{t}\right)$ a partir del valor de un aclaramiento corporal histórico $\left(\mathrm{CL}_{h}\right)$ de MFX (97 mL.kg.h) estimado por Waxman (2004) en cabras de tres semanas de vida utilizando la ecuación 5 .

$$
F_{t}=\frac{C L_{h}}{C L / F}
$$

Ecuación 5

Donde $\mathrm{CL} / \mathrm{F}$ corresponde a los valores de aclaramiento corporal $(\mathrm{CL})$, estimados con análisis no compartimental de los perfiles plasmáticos obtenidos tras la administración extravascular según la siguiente ecuación:

$$
\frac{C L}{F}=\frac{D}{A B C_{e v}}
$$

Ecuación 6

Donde $A B C_{e v}$ es el área bajo la curva obtenida tras la administración extravascular. El resto de los símbolos de las ecuaciones 5 y 6 ya fueron explicados. Los índices PK/PD utilizados para evaluar la eficacia de MFX sobre E. coli (ATCC 25922) fueron: tiempo de concentraciones por encima de la CIM ( $\mathrm{t}>\mathrm{CIM}$ ); tiempo de concentraciones por encima de la CIM expresado como \% del intervalo entre dosis $(\tau)(f \mathrm{t}>\mathrm{CIM})$; tiempo de concentraciones por encima de la CPM ( $t>C P M)$; tiempo de concentraciones por encima de la CPM expresado como $\%$ de $\tau(f \mathrm{t}>\mathrm{CPM})$; relación entre la concentración máxima y la $\mathrm{CIM}\left(\mathrm{C}_{\max } / \mathrm{CIM}\right)$; relación entre la concentración máxima y la $C P M\left(C_{\max } / C P M\right)$; relación entre el $A B C$ y la $\mathrm{CIM}(\mathrm{ABC} / \mathrm{CIM})$ y relación entre el $\mathrm{ABC}$ y la $\mathrm{CPM}(\mathrm{ABC} /$ CPM). En este estudio se utilizó el valor del $A B C$ extrapolada al infinito $\left(A B C_{0-\infty}\right)$ y no el clásico valor de $A B C_{0 \text { - }}$ 24 porque en un esquema de tratamiento de administración diaria, ambos parámetros presentan idénticos valores (Toutain et al. 2007).

Los valores de corte de cada índice fueron: $f \mathrm{t}>\mathrm{CIM}>60$ 70\%; $f \mathrm{t}>\mathrm{CPM}$ (aún sin valor reportado); $\mathrm{C}_{\max } / \mathrm{CIM} \geq 8$ 10; $\mathrm{C}_{\max } / \mathrm{CPM}$ (aún sin valor reportado); $\mathrm{ABC} / \mathrm{CIM} \geq 125$ $\mathrm{h}$ (Canut Blasco et al. 2015) y $A B C / C P M \geq 22$ h (Olofsson et al. 2006).

La estimación de la dosis de MFX capaz de proteger al 95\% de una población de cabras se estimó integrando la variabilidad de los parámetros farmacocinéticos y la sensibilidad de la cepa bacteriana en estudio a un modelo farmacocinético de administración extravascular. Brevemente; partir de la inspección del modelo presentado en la ecuación 3 , inferimos que la mayor fuente de variabilidad de la respuesta farmacocinética de MFX es debida a la varianza de los valores de $V_{d} / F$ y $\mathrm{k}_{\mathrm{e}}$. Amparándonos en el teorema del límite central, asumimos que los valores de estos parámetros dentro de una población presentan distribución normal (Le Cam, 1986), por lo que para $V_{d} / F$ y $k_{e}$ se estimaron el límite inferior $\left(L_{1}\right)$ y el límite superior $\left(L_{S}\right)$ del intervalo de tolerancia al $95 \%$ con un intervalo de confianza del 95\% según se describe a continuación:

$$
\begin{aligned}
& L_{I}=H-\lambda \cdot s \\
& L_{S}=H+\lambda \cdot s
\end{aligned}
$$

Ecuación 7

$\lambda=\frac{t_{1-\alpha, n-1} \cdot \delta}{\sqrt[2]{n}}$

Ecuación 8

$$
\delta=Z_{\alpha} \cdot \sqrt[2]{n}
$$

Ecuación 9

Donde $\mathrm{H}$ es el valor promedio, $t_{1-\alpha, n-1}$ es el valor crítico de la distribución de $t$ de student, $Z_{\alpha}$ es el valor crítico de la distribución de $Z$ y $n$ es el tamaño de la muestra. Los demás símbolos ya fueron explicados. 
El desvío estándar de los valores de $\mathrm{V}_{\mathrm{d}} / \mathrm{F}_{\text {y }} \mathrm{k}_{\mathrm{e}}$ estimados con el modelo de un compartimiento se calculó en función de los coeficientes de variación de estos parámetros obtenidos tras el análisis no compartimental. Los valores estimados de los $L_{i}$ y $L_{s}$ de $V_{d} / F$ y $k_{a}$ se organizaron en cuatro combinaciones posibles, tal como se describen en la Tabla 1.

Tabla 1. Combinaciones posibles de los valores promedio $(\mathrm{H})$ y de los límites inferior $\left(L_{1}\right)$ y superior $\left(L_{s}\right)$ de los intervalos de tolerancia al $95 \%$ de $V_{d} / F$ y $k_{e} . V_{d} / F$ es el volumen de distribución sobre la fracción biodisponible y $k_{e}$ es la constante de eliminación de primer orden aparente.

\begin{tabular}{|c|c|c|c|c|c|}
\hline \multirow{2}{*}{$\begin{array}{c}\text { Parámetros } \\
\text { farmacocinéticos }\end{array}$} & \multirow[b]{2}{*}{ Valores promedio } & \multicolumn{4}{|c|}{ Combinaciones } \\
\hline & & A & B & C & D \\
\hline $\mathbf{k}_{\mathrm{e}}$ & $\mathrm{H}$ & $\mathrm{L}_{1}$ & $\mathrm{~L}_{\mathrm{s}}$ & $L_{1}$ & Ls \\
\hline$V_{d} / F$ & $\mathrm{H}$ & $L_{s}$ & $L_{1}$ & $L_{1}$ & $\mathrm{~L}_{s}$ \\
\hline
\end{tabular}

La dosis de MFX se estimó con la ecuación 10.

$$
\text { Dosis }=\frac{A \cdot E \cdot C L}{f_{u} \cdot F}
$$

Ecuación 10

Donde $A$ es el parámetro farmacodinámico de actividad antibacteriana (CIM o CPM), E es el valor o punto de corte del índice de eficacia PK/PD; $125 \mathrm{~h}$ para ABC/CIM o $22 \mathrm{~h}$ para $A B C / C P M, f_{u}$ es la fracción libre en plasma y $F$ es la fracción biodisponible. Dado que en este trabajo no se estimó el valor real de $F$, asumimos para este parámetro un valor más o menos constante, por lo que la ecuación 10 fue modificada eliminando el valor de $F$ como divisor e incorporándolo al valor del CL, que estimado tras una administración extravascular es igual a $\mathrm{CL} / \mathrm{F}$, por lo que las dosis de MFX para lograr valores de $A B C / C I M \geq 125 h$ y de $A B C / C P M \geq 22 h$ con las cuatro combinaciones de los $L_{1}$ y $L_{s}$ de $V_{d} / F$ y $k_{e}$ se estimaron con las ecuaciones 11 y 12 .

$$
\begin{aligned}
& \text { Dosis }=\frac{C I M \cdot 125 \cdot C L / F}{f_{u}} \\
& \text { Dosis }=\frac{C P M \cdot 22 \cdot C L / F}{f_{u}}
\end{aligned}
$$

Ecuación 11

Ecuación 12

Donde el valor del $\mathrm{CL} / \mathrm{F}$ para cada simulación fue calculado con la ecuación 13.

$$
C L / F=k_{e} \cdot V_{d} / F
$$

Ecuación 13

Donde los valores de $k_{e}$ y $V_{d} / F$ corresponden a los valores estimados de los $L_{1}, L_{S}$ y promedio de cada parámetro, 125 y 22 corresponden a los valores de punto de corte para evaluar la eficacia de MFX para garantizar la cura bacteriológica y para prevenir la emergencia de cepas resistentes respectivamente $y f_{u}$ es la fracción no unida a proteínas plasmáticas o fracción libre. Las dro- gas con bajo porcentaje de unión a proteínas plasmáticas como MFX (<30\%), presentan una cinética de unión a proteínas de tipo lineal (Mehvar, 2005) donde ante una disminución de la concentración de la forma libre, el equilibrio entre la forma libre y la forma unida es un proceso que resulta en una constante e instan-tánea concentración de fármaco en forma libre (Li et al. 2015). Así las concentraciones totales en plasma de este tipo de drogas pueden considerarse como farma-cológicamente activas y se puede asumir para la $f_{u}$ de MFX un valor de 1 (Lei et al. 2017).

El ajuste de las concentraciones plasmáticas promedio y la simulación de los cuatro perfiles de concentración plasmática resultantes de las combinaciones de $k_{e} y$ $V_{d} / F$ de MFX fueron realizados con el software ADAPT II (BMSR, University of Southern California). Seguidamente, para cada perfil simulado se estimaron los parámetros farmacocinéticos fundamentales para realizar el cálculo de los índices PK/PD con los valores de CIM y CPM

\section{Resultados}

El valor de CIM de MFX para E. coli (ATCC 25922) estimado con el método de macrodilución en tubo fue de $0,0312 \mu \mathrm{g} / \mathrm{mL}$ que está comprendido en el intervalo de valores de la CIM de cepas autóctonas sensibles $(0,015$ $\mu \mathrm{g} / \mathrm{mL}$ y $0,03 \mu \mathrm{g} / \mathrm{mL}$ ) reportados por Wetzstein, (2005). Los valores de CBM y CEBM estimados con el mismo método no presentaron diferencias, siendo de 0,0624 $\mu \mathrm{g} / \mathrm{mL}$, mientras que el valor de la CPM de MFX sobre $E$. coli (ATCC 25922) fue estimada en 0,1 $\mu \mathrm{g} / \mathrm{mL}$.

Las curvas de crecimiento y muerte de E. coli (ATCC 25922) enfrentada a concentraciones crecientes de MFX se presentan en la Figura $1 \mathrm{a}$. El ajuste del $\log _{10}$ del número de bacterias sobrevivientes luego de una exposición de $24 \mathrm{~h}$ a concentraciones crecientes de MFX se presenta en la Figura $1 \mathrm{~b}$ y los parámetros estimados con el modelo sigmoideo de respuesta máxima se presentan en la Tabla 2.

Las concentraciones estimadas de MFX asociadas a los efectos bacteriostático (CIM), bactericida (CBM) y erradicación bacteriana (CEBM) estimadas con el modelo sigmoideo de respuesta máxima se presentan en la Tabla 3.

A los fines de evaluar la respuesta poblacional de la actividad de MFX sobre E. coli (ATCC 25922), para la evaluación PK/PD y el cálculo de la dosis se utilizó el valor de la CIM estimada por el método de macrodilución $(0,0312 \mu \mathrm{g} / \mathrm{mL})$. Por el contrario, como el valor de la CPM obtenida en este ensayo fue bajo $(0,1$ $\mu \mathrm{g} / \mathrm{mL}$ ), este fue reemplazado por el valor histórico de $0,5 \mu \mathrm{g} / \mathrm{mL}$ para cepas autóctonas de $E$. coli. reportado por Wetzstein, (2005). 

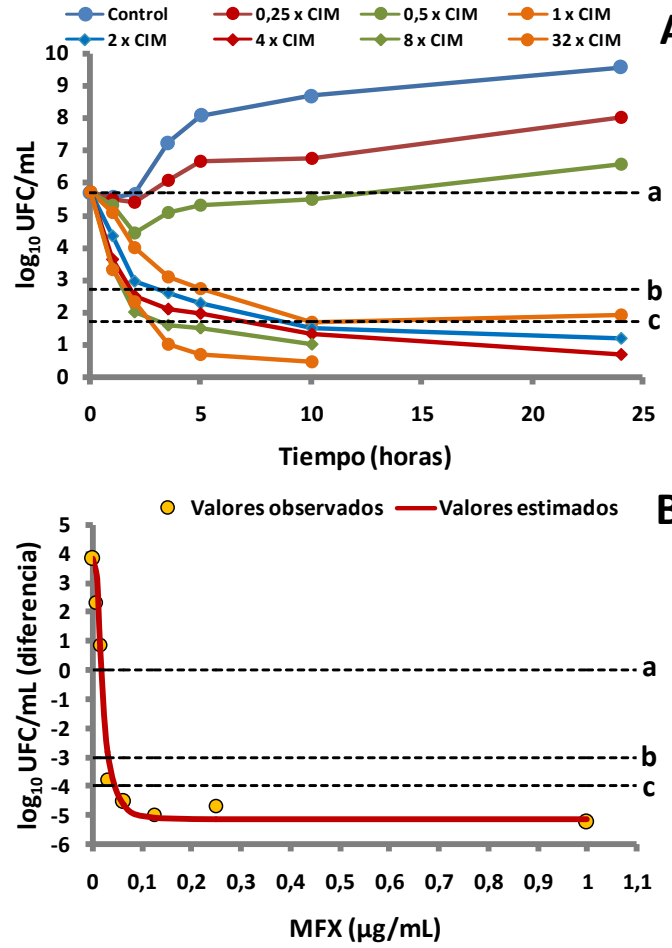

Figura 1. (A) Curvas de muerte de E. coli (ATCC 25922) expuesta a concentraciones crecientes de marbofloxacina; (B) ajuste del $\log _{10}$ del conteo de bacterias sobrevivientes tras $24 \mathrm{~h}$ de exposición con el modelo sigmoideo de respuesta máxima o de Hill. Las líneas de puntos horizontales indican la reducción de bacterias viables compatibles con: (a) actividad bacteriostática; (b) actividad bactericida y (c) actividad de erradicación bacteriana.

Tabla 2. Parámetros farmacodinámicos estimados por el ajuste del $\log _{10}$ del conteo de bacterias sobrevivientes de E. coli (ATCC 25922 ) tras $24 \mathrm{~h}$ de exposición a marbofloxacina con el modelo sigmoideo de respuesta máxima o de Hill. $E_{0}$ es el efecto o respuesta de base, $E_{\max }$ es el efecto o respuesta máxima, $C_{50}$ es la concentración de MFX que logra el $50 \%$ de $E_{\max }$ y $\alpha$ es el coeficiente de sigmoidicidad.

\begin{tabular}{|ll|}
\hline Parámetros de ajuste \\
\hline$E_{0}\left(\log _{10}\right.$ ufc/mL) & 3,850 \\
\hline$E_{\max }\left(\right.$ reducción $\log _{10}$ ufc/mL) & $-9,002$ \\
\hline$C_{50}(\mu \mathrm{g} / \mathrm{mL})$ & 0,021 \\
\hline $\boldsymbol{\alpha}$ & 2,580 \\
\hline
\end{tabular}

Tabla 3. Valores de las concentraciones de marbofloxacina para obtener el efecto bacteriostático, bactericida y de erradicación bacteriana sobre E. coli ATCC (25922). Los valores fueron calculados a partir de los parámetros farmacodinámicos estimados con el modelo de respuesta máxima o de Hill. CIM es la concentración inhibitoria mínima; CBM es la concentración bactericida mínima y CEBM es la concentración de erradicación bactericida mínima.

\begin{tabular}{|llll|}
\hline Actividad & $\begin{array}{l}\text { Parámetros } \\
\text { equivalentes }\end{array}$ & $\begin{array}{l}\text { Reducción } \\
\log _{10} \text { ufc } / \mathrm{mL}\end{array}$ & $(\mu \mathrm{g} / \mathrm{mL})$ \\
\hline Bacteriostática & CIM & 0 & 0,018 \\
\hline Bactericida & CBM & -3 & 0,032 \\
\hline Erradicación & CEBM & -4 & 0,043 \\
\hline
\end{tabular}

La evolución temporal de las concentraciones plasmáticas de MFX obtenidas tras su administración por vía SC a la dosis de $2 \mathrm{mg} / \mathrm{kg}$ en cabras de tres semanas de vida se presentan en la Figura $2 a$ y las concentraciones estimadas de MFX obtenidas por el ajuste de los datos experimentales con el modelo de un compartimiento con absorción y eliminación de orden uno se presentan en la Figura $2 b$.
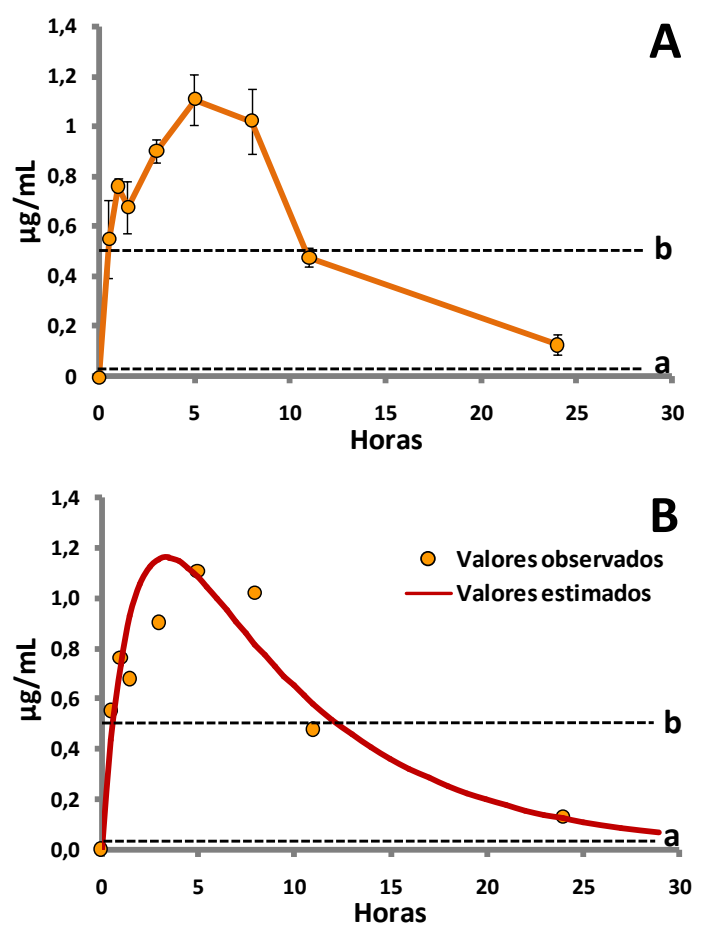

Figura 2. (A) Perfil de concentración plasmática de marbofloxacina tras su administración subcutánea a cabras de tres semanas de edad a la dosis de $2 \mathrm{mg} / \mathrm{kg}$. Los valores se hallan expresados como promedio y desvío estándar; (B) Concentraciones plasmáticas promedio de marbofloxacina (valores observados y valores estimados con un modelo de un compartimiento). Las líneas de puntos horizontales (a) y (b) indican la concentración inhibitoria mínima estimada en este ensayo $(0,0312 \mu \mathrm{g} / \mathrm{mL})$ y la concentración preventiva de mutantes histórica $(0,5 \mu \mathrm{g} / \mathrm{mL})$ reportada por Wetzstein (2005).

Los parámetros farmacocinéticos y farmacodinámicos de MFX tras su administración SC a la dosis de $2 \mathrm{mg} / \mathrm{kg}$ en cabras de tres semanas de vida estimados con análisis no compartimental y compartimental se presentan en la Tabla 4. La dosis estimadas de MFX para obtener una relación $A B C / C I M \geq 125 h$ y $A B C / C P M \geq 22$ h para las cinco combinaciones posibles de los LI y LS de Vd/F y ke fueron de $1,127 \mathrm{mg} / \mathrm{kg}$ y $3,179 \mathrm{mg} / \mathrm{kg}$ respectivamente. Los parámetros farmacocinéticos simulados para la dosis de $1,127 \mathrm{mg} / \mathrm{kg}$ se presentan en la Tabla 5 . Los parámetros farmacocinéticos simulados para la dosis de $3,179 \mathrm{mg} / \mathrm{kg}$ se presentan en la Tabla 6.

Los perfiles plasmáticos simulados de MFX tras la administración de una dosis de $3,179 \mathrm{mg} / \mathrm{kg}$ utilizando las cuatro combinaciones posibles de $L_{l}$ y $L_{s}$ de $V_{d} / F$ y $k_{e}$ 
permitieron delimitar un área de probabilidad de ocurrencia de los perfiles de concentración plasmática del 95\% de una población de cabras de tres semanas de vida. El perfil máximo se obtuvo con los valores de los $L_{l}$ de $V_{d} / F$ y $k_{e}$, mientras que el perfil mínimo se obtuvo con los valores de los $L_{s}$ de $V_{d} / F$ y $k_{e}$, tal como se presenta en la Figura 3.

Tabla 4. Parámetros farmacocinéticos y farmacodinámicos de marbofloxacina tras su administración subcutánea (SC) a la dosis de $2 \mathrm{mg} / \mathrm{kg}$ en cabras de tres semanas de vida, estimados mediante análisis no compartimental y con un modelo de un compartimiento con absorción y eliminación de orden uno. Los parámetros estimados con el método no compartimental se presentan como valores promedio $(n=6)$, desvío estándar (DE) y coeficiente de variación (CV). Los parámetros estimados con análisis compartimental corresponden al único perfil estimado de concentraciones plasmáticas promedio. El valor de CIM de E. coli (ATCC 25922) considerado fué $0,0312 \mu \mathrm{g} / \mathrm{mL}$ y para la CPM se consideró el valor histórico de $0,5 \mu \mathrm{g} / \mathrm{mL}$ de cepas autóctonas reportado por Wetzstein (2005).

\begin{tabular}{|c|c|c|c|c|}
\hline \multirow{3}{*}{$\begin{array}{c}\text { Parámetros } \\
\text { farmacocinéticos }\end{array}$} & \multicolumn{4}{|c|}{ Método de análisis } \\
\hline & \multicolumn{3}{|c|}{ No compartimental } & \multirow{2}{*}{$\begin{array}{c}\text { Compartimental } \\
\text { Estimados }\end{array}$} \\
\hline & Promedio & SD & CV (\%) & \\
\hline$k_{a}\left(h^{-1}\right)$ & - & - & & 0,48 \\
\hline$t_{1 / 2 a}(h)$ & - & - & & 1,45 \\
\hline$k_{e}\left(h^{-1}\right)$ & 0,122 & 0,020 & 16,39 & 0,119 \\
\hline$t_{1 / 2 e}(h)$ & 5,83 & 1,10 & 18,92 & 5,81 \\
\hline$t_{\max }(h)$ & 6 & 1,54 & 25,67 & 4 \\
\hline$C_{\max }(\mu \mathrm{g} / \mathrm{mL})$ & 1,14 & 0,12 & 10,58 & 1,09 \\
\hline $\mathrm{V}_{\mathrm{d}} / \mathrm{F}(\mathrm{mL} / \mathrm{kg})$ & 1165,7 & 236,5 & 20,28 & 1152,7 \\
\hline CL/F (mL.kg.h) & 138,9 & 14,9 & 10,72 & 137,5 \\
\hline$F_{t}$ & 0,72 & 0,071 & 0,099 & 0,70 \\
\hline$A B C_{0-\infty}(\mu \mathrm{g} \cdot \mathrm{h} / \mathrm{mL})$ & 14,5 & 1,44 & 10,73 & 14,5 \\
\hline $\mathrm{ABC} / \mathrm{CIM}(\mathrm{h})$ & 465,6 & 46,0 & 9,88 & 466,1 \\
\hline ABC/CPM (h) & 29,1 & 2,87 & 9,88 & 29,1 \\
\hline $\mathrm{C}_{\max } / \mathrm{CIM}$ & 36,6 & 3,87 & 10,58 & 35,0 \\
\hline $\mathrm{t}>\mathrm{CIM}$ (h) & 26,2 & 0,98 & 3,76 & 31 \\
\hline$f \mathrm{t}>\mathrm{CIM}(\%)$ & 109,0 & 4,10 & 3,76 & 129,2 \\
\hline $\mathrm{C}_{\max } / \mathrm{CPM}$ & 2,28 & 0,24 & 10,58 & 2,19 \\
\hline$t>C P M(h)$ & 10,6 & 1,03 & 9,75 & 12,5 \\
\hline$f \mathrm{t}>\mathrm{CPM}(\%)$ & 44,1 & 4,30 & 9,75 & 52,1 \\
\hline
\end{tabular}

$k_{a}$ y $k_{e}$ son las constantes de primer orden aparente de absorción y eliminación respectivamente; $t_{1 / 2 a}$ y $t_{1 / 2 e}$ son las semividas de absorción y eliminación de primer respectivam orden, $C_{\max }$ es la máx $C_{\max } ; V_{d} / F$ es el volumen de distribución aparente sobre la fracción biod $\mathrm{CL} / \mathrm{F}$ es el aclaramiento corporal sobre la fracción biodisponible; $\mathrm{F}_{\mathrm{t}}$ es la fracción biodisponible teórica; $A B C_{0-\infty}$ es el área bajo la curva de concentración plasmática extrapolada al infinito; $A B C / C I M$ y $A B C / C P M$ son la relación entre el $A B C$ y la concentración inhibitoria mínima y la concentración preventiva de mutantes respectivamente; $C_{\max } / \mathrm{CIM}_{\text {y }} \mathrm{C}_{\max } / \mathrm{CPM}$ son índices de eficacia para antibióticos con actividad dependiente de la concentración; $\mathrm{t}>\mathrm{CIM}$ y $f \mathrm{t}>\mathrm{CIM}$ son la permanencia de concentraciones plasmáticas mayores a l CIM expresadas como tiempo y como fración de interalo de dosficación de $24 \mathrm{~h}$ respectivamente; $>C P M$ Y $f(D C M$ 佂 son la permanencia de concentraciones plasmáticas mayores a la CPM expresadas como tiempo y como fracción del intervalo de dosificación respectivamente.

\section{Discusión}

Una antibioterapia óptima se basa en la selección del antimicrobiano y la dosis que consiguen los mejores resultados clínicos con los mínimos efectos adversos para el paciente y el mínimo impacto en el desarrollo de resistencia, de manera que la idoneidad de un trata- miento antibiótico no solo está condicionada por la adecuada selección del antibiótico en base a la bacteria aislada y su sensibilidad, sino que también va a depender del régimen de dosificación seleccionado.

Los cabritos durante sus primeras semanas de vida pueden ser considerados pacientes críticos, los que en la terapéutica antibiótica merecen una consideración especial, ya que en esta población se dan las situaciones de mayor riesgo, tanto de fracaso terapéutico como de selección de resistencias. Aunque las FQs en general son efectivas para el tratamiento de infecciones gastrointestinales en rumiantes causadas por $E$. coli, este grupo de antimicrobianos es considerado de segunda elección y su uso debe reservarse cuando ya se ha detectado resistencia a otros antibióticos como los betalactámicos, la tetraciclina y la asociación sulfonamidas trimetoprina.

Para garantizar una eficacia óptima y reducir la selección de resistencia, los regímenes de dosificación de las FQs deben determinarse cuidadosamente sobre la base de sus propiedades PK y PD. El estudio PK-PD de MFX y la estimación de una dosis para tratar infecciones asociadas a $E$. coli y proteger al $95 \%$ de cabritos de tres semanas de vida, obedece a la necesidad de evitar el uso empírico de una dosis extrapolada de la especie bovina y optimizar la posología de MFX para evitar la emergencia de resistencia.

En este estudio los resultados obtenidos en las curvas de muerte bacteriana mostraron que MFX presentó un perfil bactericida bifásico. Durante las primeras cinco horas se observó una actividad concentración dependiente, donde la velocidad de eliminación bacteriana se incrementó en forma proporcional al incremento de las concentraciones. A partir de la quinta hora de actividad se produjo un quiebre en la cinética bactericida y la velocidad de eliminación bacteriana se redujo en casi todas las concentraciones mayores a $0,5 \times \mathrm{CIM}$ y a partir de las $10 \mathrm{~h}$ la velocidad de eliminación de las bacterias se tornó similar para todas las concentraciones y la reducción del número de bacterias viables pasó a depender del tiempo de exposición a MFX (Figura 1a). En cuanto a la eficacia, se observó que todas las concentraciones de MFX $\geq 2 \times \mathrm{CIM}$ fueron suficientes para reducir el número de bacterias viables en un 99,99\%, lo cual es equivalente a una actividad de erradicación bacteriana. Similares resultados fueron reportados para ciprofloxacina y enrofloxacina sobre cepas de E. coli (Siroski et al. 2015; Patricelli y col., 2016; Patricelli y col., 2017; Gray et al. 2017). Estos hallazgos concuerdan con la actividad codependiente de la concentración y el tiempo de exposición reportada para FQs (Blot et al. 2014).

La curva de muerte bacteriana (Figura 1a) muestra la actividad mixta de MFX sobre E. coli (ATCC 25922), lo que corrobora el empleo de un índice PK-PD que priorice el tiempo de exposición $(A B C / C I M)$ a un elevado pico de concentración por poco tiempo $\left(\mathrm{C}_{\max } / \mathrm{CIM}\right)$. De 
todos modos, la rápida velocidad bactericida observada a elevadas concentraciones, tendría su efecto favorable al reemplazar la CIM por la CPM como parámetro farmacodinámico de referencia $(A B C / C P M)$ para evitar la emergencia de cepas resistentes.

El coeficiente de Hill $(\alpha)$ estimado con el modelo sigmoideo de respuesta máxima presentó un valor $>1$ $(2,580)$, lo que se interpreta como una relación concentración-efecto de tipo todo o nada, donde a partir de pequeños incrementos en las concentraciones de MFX se puede pasar de la ausencia de eficacia a la eficacia máxima (Figura 1b). Este fenómeno explica por qué los valores de la CBM y la CEBM hallados con el método de macrodilución en tubo fueron idénticos $(0,0624 \mu \mathrm{g} / \mathrm{mL})$ y equivalentes a $2 \times \mathrm{CIM}$. Por el contrario, el modelo sigmoideo permitió estimar las concentraciones teóricas de CIM, CBM y CEBM, que fueron menores a los valores estimados con el método de macrodilución (Tabla 3). Sin embargo, en este estudio como factor de seguridad se prefirió utilizar el valor sobredimensionado de CIM estimado por este último método.

Debido al bajo valor de CPM estimado para E. coli (ATCC 25922), para estimar la dosis de MFX se optó por utilizar el valor histórico de la CPM reportado por Wetzstein $(2005)$ de $(0,5 \mu \mathrm{g} / \mathrm{mL})$. El bajo valor observado de CPM de E. coli (ATCC 25922) puede deberse a dos factores: (i) baja velocidad de mutación, ya que las mutaciones espontáneas ocurren en el orden de $10^{-9}-10^{-10}$ por generación durante la replicación del ADN (Olofsson y Cars, 2007), lo que determina que para poder observar una cepa mutante se requieren poblaciones bacterianas de concentración elevada del orden de $10^{9}-10^{10} \mathrm{ufc} / \mathrm{mL}$ (Blondeau, 2009), por lo que la presencia de bacterias mutantes sería poco probable observar en la limitada carga bacteriana de un repique y (ii) baja frecuencia de mutación, debido a que en un repique bacteriano la ausencia de presión de selección por ausencia de antibiótico no favorecería la amplificación de una la subpoblación resistente ya presente.

Tabla 5. Parámetros farmacocinéticos y farmacodinámicos simulados de marbofloxacina tras la administración SC de una dosis de 1,127 $\mathrm{mg} / \mathrm{kg}$. La dosis logró una relación $A B C / C I M \geq 125 \mathrm{~h}$ para las cuatro combinaciones posibles de $L_{1}$ y $L_{s}$ de $V_{d} / F$ y $k_{e}$. El valor de $C I M$ de $E$. coli (ATCC 25922) considerado fue de $0,0312 \mu \mathrm{g} / \mathrm{mL}$. $L_{1} y L_{s}$ corresponden a los valores de los límites superior e inferior de los intervalos de tolerancia al $95 \%$ de $k_{e} y V_{d} / F$ respectivamente. El resto de los símbolos fueron explicados anteriormente.

\begin{tabular}{|c|c|c|c|c|c|}
\hline \multirow[t]{2}{*}{ Parámetros } & \multirow[t]{2}{*}{ Promedio } & \multicolumn{4}{|c|}{ Combinaciones } \\
\hline & & A & B & C & D \\
\hline$k_{a}\left(h^{-1}\right)$ & 0,477 & 0,477 & 0,477 & 0,477 & 0,477 \\
\hline$k_{e}\left(h^{-1}\right)$ & 0,119 & $0,072^{(\text {LI) }}$ & $0,167^{(\text {LS) }}$ & $0,072^{(\mathrm{LI})}$ & $0,167^{(\text {LS) }}$ \\
\hline $\mathrm{V}_{\mathrm{d}} / \mathrm{F}(\mathrm{mL} / \mathrm{kg})$ & 1152,7 & $1730,2^{(\text {LS) }}$ & $575,1^{(\text {니 })}$ & $575,1^{(\text {LI) }}$ & $1730,2^{(\text {LS) }}$ \\
\hline CL/F (mL.kg.h) & 137,5 & 123,8 & 96,1 & 41,1 & 289,1 \\
\hline$t_{\max }(h)$ & 4,0 & 4,5 & 3,5 & 4,5 & 3,5 \\
\hline$C_{\max }(\mu \mathrm{g} / \mathrm{mL})$ & 0,62 & 0,47 & 1,11 & 1,40 & 0,37 \\
\hline$A B C_{0-\infty}(\mu \mathrm{g} \cdot \mathrm{h} / \mathrm{mL})$ & 8,2 & 9,1 & 11,7 & 27,4 & 3,9 \\
\hline $\mathrm{ABC} / \mathrm{CIM}(\mathrm{h})$ & 262,8 & 291,9 & 376,1 & 878,3 & 125,0 \\
\hline $\mathrm{C}_{\max } / \mathrm{CIM}$ & 19,7 & 14,9 & 35,7 & 44,9 & 11,9 \\
\hline $\mathrm{t}>\mathrm{CIM}$ (h) & 24,0 & 24,0 & 24,0 & 24,0 & 11,9 \\
\hline$f \mathrm{t}>\mathrm{CIM}(\%)$ & 100,0 & 100,0 & 100,0 & 100,0 & 83,3 \\
\hline
\end{tabular}

Tabla 6. Parámetros farmacocinéticos y farmacodinámicos simulados de marbofloxacina tras la administración SC de una dosis de 3,179 $\mathrm{mg} / \mathrm{kg}$. La dosis logró una relación $A B C / C P M \geq 22 \mathrm{~h}$ para las cuatro combinaciones posibles de $L_{l}$ y $L_{s}$ de $V_{d} / F$ y $k_{e}$. El valor de la $C P M$ de $E$. coli considerado fué el valor histórico de $0,5 \mu \mathrm{g} / \mathrm{mL}$ estimado para cepas autóctonas reportado por Wetzstein (2005). $\mathrm{L}_{\mathrm{l}} \mathrm{y} \mathrm{L}_{\mathrm{s}}$ corresponden a los valores de los límites superior e inferior de los intervalos de tolerancia al $95 \%$ de $k_{e} y V_{d} / F$ respectivamente. El resto de los símbolos fueron explicados anteriormente.

\begin{tabular}{|c|c|c|c|c|c|}
\hline \multirow[t]{2}{*}{ Parámetros } & \multirow[t]{2}{*}{ Promedio } & \multicolumn{4}{|c|}{ Combinaciones } \\
\hline & & A & B & C & D \\
\hline$k_{a}\left(h^{-1}\right)$ & 0,477 & 0,477 & 0,477 & 0,477 & 0,477 \\
\hline$k_{e}\left(h^{-1}\right)$ & 0,119 & $0,072^{(\text {LII }}$ & $0,167^{(\text {LS })}$ & $0,072^{(\text {LI) }}$ & $0,167^{(\text {LS })}$ \\
\hline $\mathrm{V}_{\mathrm{d}} / \mathrm{F}(\mathrm{mL} / \mathrm{kg})$ & 1152,7 & $1730,2^{(\text {LS }}$ & $575,1^{\text {(LI) }}$ & $575,1^{(\text {LI) }}$ & $1730,2^{(\text {LS })}$ \\
\hline CL/F (mL.kg.h) & 137,5 & 123,8 & 96,1 & 41,1 & 289,1 \\
\hline$t_{\max }(h)$ & 4,0 & 4,5 & 3,5 & 4,5 & 3,5 \\
\hline$C_{\max }(\mu \mathrm{g} / \mathrm{mL})$ & 1,74 & 1,31 & 3,14 & 3,95 & 1,04 \\
\hline$A B C_{0-\infty}(\mu \mathrm{g} \cdot \mathrm{h} / \mathrm{mL})$ & 23,1 & 25,7 & 33,1 & 77,3 & 11,0 \\
\hline ABC/CPM (h) & 46,2 & 51,4 & 66,2 & 154,6 & 22,0 \\
\hline $\mathrm{C}_{\max } / \mathrm{CPM}$ & 3,47 & 2,63 & 6,28 & 7,91 & 2,09 \\
\hline t>CPM (h) & 16,5 & 20,5 & 17 & 24 & 10 \\
\hline$f \mathrm{t}>\mathrm{CPM}(\%)$ & 68,8 & 85,4 & 70,8 & 100 & 41,7 \\
\hline
\end{tabular}




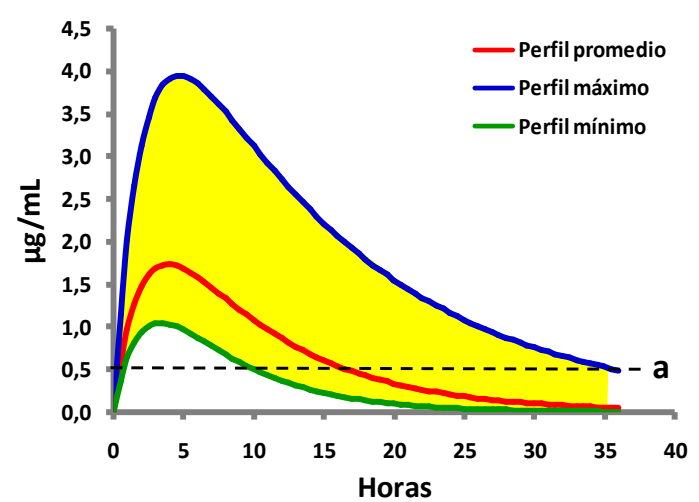

Figura 3. Gráfica del área de probabilidad de ocurrencia de un perfil de concentración plasmática de marbofloxacina en el 95\% de una población de cabras de tres semanas de vida tras la administración subcutánea de una dosis de $3,179 \mathrm{mg} / \mathrm{kg}$. El área de probabilidad sombreada en amarillo se halla delimitada por un perfil de concentración plasmática máximo que se obtuvo con los valores de $L_{l}$ de $V_{d} / F$ y $k_{e}$, mientras que el perfil mínimo se obtuvo con los valores de $L_{s}$ de $V_{d} / F$ y $k_{e}$. La línea de puntos horizontal (a) indica la concentración preventiva de mutantes histórica $(0,5 \mu \mathrm{g} / \mathrm{mL})$ reportada por Wetzstein (2005).

El elevado valor de la CPM para cepas autóctonas de $E$. coli reportado por Wetzstein (2005) podría ser explicado por la amplificación de subpoblaciones con menor sensibilidad a MFX causada por una eventual presión de selección provocada por exposición previa de las mismas al antibiótico.

La MFX se administró a cabras de tres semanas de vida con la dosis extrapolada del bovino de $2 \mathrm{mg} / \mathrm{kg}$ por vía SC, con el objeto de estimar los parámetros farmacocinéticos básicos que sirvieran de referencia para la estimación in silico de la dosis de MFX. Se utilizó la vía SC, porque tratándose de animales productores de carne, se procuró evaluar la performance de una vía de administración parenteral alternativa a la intramuscular a fin evitar dañar las masas musculares de los animales.

Al no haberse realizado un estudio de farmacocinética intravenosa (IV) de MFX, no se pudo obtener información acerca del valor real de $F$, por lo que para disponer de un valor aproximado de la misma, se calculó la $\mathrm{F}_{\mathrm{t}}$ utilizando el valor del $\mathrm{CL}_{h}$ reportado por Waxman (2004) porque: (i) al estar ya estimado y reportado, no se justificaba la duplicación de un ensayo con administración IV; (ii) el valor del $\mathrm{CL}$ reportado por Waxman (2004) fue estimado con el método trapezoidal y con una intensa frecuencia de muestreo, por lo tanto su valor es robusto e inequívoco, (iii) para contribuir al bienestar animal evitando la realización de ensayos in vivo y (iv) siendo MFX un a ATB de segunda elección, una administración IV para estimar un parámetro $\mathrm{PK}$ ya disponible en la literatura $(\mathrm{CL})$ suponía una nueva exposición de las cepas de $E$. coli comensales intestinales al ATB y un riesgo innecesario de seleccionar cepas con menor sensibilidad a MFX
El valor estimado de $F_{t}$ de MFX calculado con la ecuación $4(>0,7)$ proporcionó solo una aproximada información acerca de $\mathrm{F}$ de la dosis utilizada en este estudio ( $2 \mathrm{mg} / \mathrm{kg}$ ). Sin embargo el valor estimado de $F_{t}$ es cercano a los reportados para bovinos, ovinos y búfalos cuyos valores promedios fluctuaron entre 0,89 y 1,14 (Aliabadi y Lees, 2002; Ismail and El-Kattan, 2007; Sidhu et al. 2010).

La ausencia de un valor real de F, planteó una limitación al momento de ajustar los datos experimentales con la ecuación de Bateman (Ecuación 3), ya que no se pudo utilizar el valor de la dosis corregido por el valor de $\mathrm{F}$ (Dosis $\times$ F), por lo tanto la ecuación se modificó para eliminar de la misma el valor de $F$ (Ecuación 4), quedando implícitamente incorporado a la misma en el valor estimado de $V_{d}$ como $V_{d} / F$. Al calcular mediante regresión no lineal ponderada de mínimos cuadrados los valores estimados de concentración plasmática de MFX (Figura 2B), el modelo eliminó la variabilidad interindividual de los datos experimentales simulando el mejor perfil promedio estimado de MFX en cabras de tres semanas de vida (Figura 2B).

A partir de los resultados obtenidos en el análisis no compartimental (Tabla 4), se puede observar que la administración de una dosis de $2 \mathrm{mg} / \mathrm{kg}$ de MFX en cabras de tres semanas de vida $(n=6)$ originó perfiles de concentración plasmática que permitieron estimar valores de $A B C / C I M>125 h(465,6 \pm 46 h)$ y de $\mathrm{ABC} / \mathrm{CPM}>22 \mathrm{~h}(29,1 \pm 2,87 \mathrm{~h})$, que permitirían inferir $a$ priori que la dosis extrapolada del bovino de $2 \mathrm{mg} / \mathrm{kg}$ sería adecuada para garantizar la remisión clínica y prevenir la emergencia de cepas resistentes de $E$. coli.

Sin embargo, aunque la dosis estimada de MFX a partir de una muestra constituida por seis individuos pueda aparentar ser satisfactoria, es improbable que la misma sea óptima a nivel poblacional, ya que la variabilidad interanimal de exposición de la bacteria al antibiótico es el principal factor que favorece la emergencia de resistencia. De esta manera cuando se considera la variabilidad de los parámetros farmacocinéticos en estudio $\left(k_{e}\right.$ y $V_{d} / F$ ) se pueden estimar los índices PK-PD no solo del promedio, sino de todos los individuos de una población. De esta manera la combinación de los valores de los parámetros PK permite expandir la información obtenida a partir de una muestra, permitiendo ver todos los resultados posibles de observarse en una población. Básicamente consiste en un procedimiento que combina la sensibilidad de agente patógeno expresada como índices de eficacia $(A B C / C I M \quad 0$ $A B C / C P M)$, un modelo farmacocinético determinado $y$ la variabilidad de la exposición del agente antimicrobiano, la que resulta de la distribución de los parámetros $P K\left(k_{e} \quad y \quad V_{d} / F\right)$ incorporados al modelo seleccionado.

Así el estudio de simulación nos permitió calcular las dosis con las cuales los individuos de una población de cabras lograrían los perfiles plasmáticos máximos y mí- 
nimos con los que se esperaría alcanzar los índices de eficacia para MFX como $A B C / C I M \geq 125$ y $A B C / C P M \geq 22$ $\mathrm{h}$ en el $95 \%$ de una población de cabras de tres semanas de vida.

El estudio de simulación de perfiles plasmáticos incorporando al modelo de un compartimiento las cuatro posibles combinaciones de $L_{1}$ y $L_{S}$ de $V_{d} / F$ y $k_{e}$, permitió inferir que una dosis de $1127,4 \mu \mathrm{g} / \mathrm{kg}(1,127 \mathrm{mg} / \mathrm{kg})$ permitiría obtener valores de $A B C / C I M \geq 125$ h (125 h 878,3 h) que serían compatibles con la remisión clínica y la cura bacteriológica en el $95 \%$ de una población de cabras de tres semanas de vida.

Considerando el esquema terapéutico propuesto para MFX de una dosis diaria cada $24 \mathrm{~h}$ durante 3-5 días, el tiempo de exposición evaluado por $f \mathrm{t}>\mathrm{CIM}$ en los perfiles simulados con esta dosis fue $>83,3 \%(83,3 \%-100$ $\%$ ) del intervalo entre dosis ( $\tau=24 \mathrm{~h}$ ), lo cual supera el límite de corte propuesto de $60-70 \%$ para éste índice PK/PD. Por otra parte al ser MFX un ATB con actividad dependiente de la concentración, la relación $C_{\max } / \mathrm{CIM}$ mostró que esta dosis logró valores que fluctuaron entre 11,9 y 49,9 , los cuales son mayores al punto de corte establecido para garantizar eficacia de $\geq 8-10$ sobre E. coli.

Este resultado demuestra que la dosis de $2 \mathrm{mg} / \mathrm{kg}$ extrapolada de la especie bovina sería adecuada para garantizar la remisión clínica y eventualmente la erradicación bacteriana en una población de cabras de tres semanas de vida. Al estar sobredimensionada, el exceso de dosis actuaría como un factor de seguridad para contrarrestar el efecto de variabilidades imprevistas tanto en la farmacocinética de MFX como en la sensibilidad de las cepas actuantes de $E$. coli.

Sin embargo el objetivo de este trabajo fue estimar una dosis de MFX que además de lograr la remisión clínica fuera a su vez capaz de evitar la emergencia de cepas resistentes utilizando como referencia de la actividad de MFX el índice ABC/CPM con un punto de corte de $\geq$ $22 \mathrm{~h}$ (Olofsson et al. 2006). Las simulaciones realizadas donde se incorporaron a la ecuación de Bateman las cuatro posibles combinaciones de los $L_{1}$ y $L_{s}$ de $V_{d} / F$ y $k_{e}$, mostraron que se necesita una dosis de $3179,9 \mu \mathrm{g} / \mathrm{kg}$ $(3,179 \mathrm{mg} / \mathrm{kg})$ para lograr valores de $A B C / C P M \geq 22 \mathrm{~h}$ $(22,0 \mathrm{~h}-154,6 \mathrm{~h})$ capaces de prevenir la emergencia de cepas resistentes de $E$. coli en el $95 \%$ de una población de cabras de tres semanas de vida. A los fines prácticos de administración esta dosis puede ser incrementada a $3,5 \mathrm{mg} / \mathrm{kg}$ a modo de factor de seguridad para contrarrestar el efecto de variabilidades imprevistas en la farmacocinética de MFX y en la presencia de bacterias con menor sensibilidad a la MFX.

Con la dosis de $3,179 \mathrm{mg} / \mathrm{kg}$, los valores estimados de $\mathrm{C}_{\max } / \mathrm{CPM}$ fluctuaron entre 2,09 y 7,91 mientras que los valores de la relación $f \mathrm{t}>\mathrm{CPM}$ se hallaron dentro del intervalo comprendido entre 41,7 y $100 \%$ (Tabla 6).
Cabría recordar que los actuales regímenes posológicos de las FQs se han diseñado considerando como objetivo terapéutico solo la remisión clínica y la erradicación bacteriana. Solo recientemente se ha prestado atención a la problemática de la selección de mutantes preexistentes o nuevas. Aún no se ha propuesto para MFX - y FQs en general - valores de corte para $\mathrm{C}_{\max } / \mathrm{CPM}$ y $f \mathrm{t}>\mathrm{CPM}$ para evaluar la eficacia del tiempo de exposición de concentraciones iguales o superiores a la CPM. Sin embargo en base a los resultados obtenidos en este estudio, podemos asumir que si los valores mínimos estimados para $C_{\max } /$ CPM $(2,09)$ y $f \mathrm{t}>\mathrm{CPM}$ $(41,7 \%)$ resultaron de perfiles de concentración plasmática que originaron valores de $A B C / C P M \geq 22 \mathrm{~h}$, entonces estos podrían ser considerados como puntos de corte de referencia aceptables para evaluar la actividad de MFX en la prevención de la emergencia de cepas resistentes de $E$. coli.

Aunque MFX es un antibiótico de uso crítico, eso no implica que no se lo use, solo que se deberá emplear en determinadas ocasiones, cuando epidemiologicamente se justifique o por realización previa de antibiograma y conocimiento de resistencias a otros antibióticos. La dosis de MFX estimada en este estudio a partir del índice PK-PD de ABC/CPM 22 de 3,179 mg/kg garantiza elevadas concentraciones para eliminar a las bacterias sensibles, lo que sumado a la prolongada exposición de las bacterias evitaría la emergencia de cepas resistentes o la amplificación de la población menos sensible ya presente.

Según los resultados obtenidos en este estudio, una dosis de MFX de $3,179 \mathrm{mg} / \mathrm{kg}$ sería suficiente para lograr en cabras de tres semanas de vida valores de ABC/CPM comprendidos entre $22,0-154,6 \mathrm{~h}$ que minimicen la emergencia de cepas resistentes de $E$. coli. Sin embargo, a los fines de facilitar la dosificación y proponemos una dosis incrementada de $3,5 \mathrm{mg} / \mathrm{kg}$ para que actúe como factor de seguridad ante eventuales variaciones imprevistas del comportamiento farmacocinético y la sensibilidad de las cepas bacterianas autóctonas.

Considerando que la correcta dosis de un antibiótico es la clave para una correcta terapéutica, un detalle no menor a la hora de garantizar una dosificación óptima, lo constituye la concentración de la solución inyectable utilizada en este ensayo $(10 \% \mathrm{p} / \mathrm{v})$. El inconveniente de esta, es que los volúmenes a inyectar en animales con un peso corporal menor a los $10 \mathrm{~kg}$ son muy bajos $(0,15$ a $0,156 \mathrm{~mL}$ ), lo que representa una incomodidad y una fuente de error que se puede superar con una solución al $1 \%$ que permitiría dosificar volúmenes 10 veces mayores, minimizando el error del operador.

La propuesta de estimar una dosis de MFX para el tratamiento de las infecciones asociadas a E. coli en cabras de tres semanas de edad persiguió un objetivo más allá del logro terapéutico, ya que con esta se buscó (i) preservar la salud de las especies menores 
productoras de alimento; (ii) evitar la emergencia de cepas bacterianas resistentes, (iii) mejorar la calidad de vida de la población rural; (iii) fomentar el cuidado del medio ambiente y por último (iiii) lograr que los investigadores actúen con responsabilidad social en la asignación y usos de los recursos públicos.

\section{Agradecimientos}

Este estudio fue realizado gracias al soporte financiero proporcionado por la Universidad Nacional del Litoral en el marco de la convocatoria de proyectos CAl+D 2016. Agradecemos la colaboración de todos los alumnos de la Carrera de Medicina Veterinaria de la FCVUNL pertenecientes al Grupo Funcional Caprinos de la FCV- UNL y a la Unidad Académico Experimental de la FCV-UNL por permitirnos hacer uso de sus instalaciones. También agradecemos al Laboratorio Allignani Hnos, SRL y en forma muy especial al Dr. Mariano Allignani por proporcionarnos el estándar de marbofloxacina $y$ haber fabricado a nuestro pedido una formulación experimental de marbofloxacina al $10 \%$ $\mathrm{p} / \mathrm{v}$.

\section{Bibliografía}

Ahmad I, Huang L, Hao H, Sanders P, Yuan Z. 2016. Application of PK/PD modeling in Veterinary Field: Dose Optimization and Drug Resistance Prediction. BioMed Res. Int. 2016: 5465678.

Albarellos GA, Montoya L, Landoni MF. 2005.

Pharmacokinetics of marbofloxacin after single intravenous and repeat oral administration to cats. J. Vet. Pharmacol. Ther. 170: 222-229.

Aliabadi FS, Lees P. 2002. Pharmacokinetics and pharmacokinetic / pharmacodynamic integration of marbofloxacin in calf serum, exudate and transudate. J. Vet. Pharmacol. Therap. 25: 161-174.

Barbour A, Scaglione F, Derendorf H. 2010. Class-dependent relevance of tissue distribution in the interpretation of antiinfective pharmacokinetic/pharmacodynamic indices. Int. J. Antimicrob. Agents. 35: 431-438.

Bateman, H. 1910. The solution of a system of differential equations occurring in the theory of radioactive transformations. Proc. Cambridge Philos. Soc. 15: 423-427.

Bedotti D, Rossanigo E. 2011. Manual de reconocimiento de enfermedades del caprino; Diagnóstico de las enfermedades más comunes en la región centro oeste del país. Ed. INTA, Anguil, La Pampa, Argentina. 27 pp.

Blondeau JM. 2009. New concepts in antimicrobial susceptibility testing: the mutant prevention concentration and mutant selection window approach. Vet. Dermatol. 20: 383-396.

Blot SI, Pea F, Lipman J. 2014. The effect of pathophysiology on pharmacokinetics in the critically ill patient-concepts appraised by the example of antimicrobial agents. Adv. Drug Deliver. Rev. 20: 3-11.
Burgess DS. 1999. Pharmacodynamic principles of antimicrobial therapy in the prevention of resistance. Chest. 115: 19S-23S.

Canut Blasco A, Aguilar Alfaro L, Cobo Reinoso J, Giménez Mestre MJ, Rodríguez-Gascón A. 2015. Análisis farmacocinético - farmacodinámico en microbiología: herramienta para evaluar el tratamiento antimicrobiano. Enferm. Infec. y Micr. Cl. 33: 48-57.

CLSI (Clinical and Laboratory Standards Institute). 2008. Development of in vitro susceptibility testing criteria and quality control parameters for veterinary antimicrobial agents; Approved guideline. $3^{\text {rd }}$ Edition, Document M37-A3, Volume 28, Number 7. Wayne, Pennsylvania USA.

de la Rosa Carbajal S. 2013. Sistemas de producción caprina de carne en el nordeste argentino. En: Memorias primer congreso argentino de producción caprina. La Rioja, Argentina. Pp. 4-16.

Ding H, Li Y, Chen Z, Rizwan-Ul-Haq M, Zeng Z. 2010. Plasma and tissue cage fluid pharmacokinetics of marbofloxacin after intravenous, intramuscular, and oral single-dose application in pigs. J. Vet. Pharmacol. Ther. 33: 507-510.

Drusano GL. 2007. Pharmacokinetics and pharmacodynamics of antimicrobials. Clin. Infect. Dis. 45: S89-S95.

Dong Y, Zhao X, Domagala J, Drlica K. 1999. Effect of fluoroquinolone concentration on selection of resistant mutants of Mycobacterium bovis BCG and Staphylococcus aureus. Antimicrob. Agents. Chemother. 43: 1756-1758.

El Garch F, Kroemer S, Galland D, Morrissey I, Woehrle F. 2017. Survey of susceptibility to marbofloxacin in bacteria isolated from diseased pigs in Europe. Vet. Rec. 180: 591.

EMEA. 1996. Marbofloxacin Summary Report (1).

EMEA/MRL/079/96-Final.

http://www.ema.europa.eu/docs/en GB/document library/M aximum Residue Limits - Report/2009/11/WC500014864.pdf

EMEA. 1999. Marbofloxacin, Summary report (2). EMEA/MRL/693/99-Final.

https://www.ema.europa.eu/en/documents/mrlreport/marbofloxacin-summary-report-2-committeeveterinary-medicinal-products en.pdf

EMA. 2016. Guideline on the use of pharmacokinetics and pharmacodynamics in the development of antimicrobial medicinal products. EMA/CHMP/594085/2015.

https://www.ema.europa.eu/en/documents/scientificguideline/guideline-use-pharmacokinetics-pharmacodynamicsdevelopment-antimicrobial-medicinal-products en.pdf.

Fina BL, Lombarte M, Rigalli A. 2013. Investigación de un fenómeno natural: ¿Estudios in vivo, in vitro o in silico? Actual. Ost. 9: $239-240$

García Rodríguez J, Cantón R, García Sánchez J, Gómez-Lus M, Martínez Martínez L, Rodríguez-Avial C, Vila J. 2001. Métodos especiales para el estudio de la sensibilidad a los antimicrobianos. En: Procedimientos en Microbiología Clínica. Sociedad Española de Enfermedades Infecciosas y Microbiología Clínica. Primera Edición. España. Pp. 1-38.

Gimenez A. 2012. ¿Qué es un meta-análisis? y ¿Cómo leerlo? Biomed. 7: 16-27.

Goutelle S, Maurin M, Rougier F, Barbaut X, Bourguignon L, Ducher M, Maire P. 2008. The Hill equation: a review of its 
capabilities in pharmacological modelling. Fundam. Clin. Pharmacol. 22: 633-648.

Gray Z, Patricelli A, Dell'Elce A, Presa Rossa C, Ramírez E, Formentini E. 2017. Effect of the bovine serum and persister cells on the efficacy of enrofloxacin and ciprofloxacin against a strain of Escherichia coli. Rev. Med. Vet. Toulouse. 168: 173182

Haritova AM, Rusenova NV, Parvanov PR, Lashev LD, Fink Gremmels J. 2006. Integration of pharmacokinetic and pharmacodynamic indices of marbofloxacin in turkeys. Antimicrob. Agents Ch. 50: 3779-3785.

Ismail M, El-Kattan YA. 2007. Comparative pharmacokinetics of marbofloxacin in healthy and Mannheimia haemolitica infected calves. Res. Vet. Sci. 82: 398-404.

Le Cam. 1986. The central limit theorem around 1935. Stat. Sci. 1: 78-96.

Lei Z, Liu Q, Xiong J, Yang B, Yang S, Zhu Q, Li K, Zhang S, Cao J, He Q. 2017. Pharmacokinetic and Pharmacodynamic Evaluation of Marbofloxacin and PK/PD Modeling against Escherichia coli in Pigs. Front. Pharmacol. 21: 542.

Li P, Fan Y, Wang Y, Lu Y, Yin Z. 2015. Characterization of plasma protein binding dissociation with online SPE-HPLC. Sci. Rep. 5: 14886.

Mehvar R. 2005. Role of protein binding in pharmacokinetics. Am. J. Pharm. Educ. 69: 1526.

Nielsen El, Friberg LE. 2013. Pharmacokinetic pharmacodynamic modeling of antibacterial drugs. Pharmacol. Rev. 65: 1053-1090.

Olofsson SK, Marcusson LL, Komp Lindgren P, Hughes D, Cars O. 2006. Selection of ciprofloxacin resistance in Escherichia coli in an in vitro kinetic model: relation between drug exposure and mutant prevention concentration. J. Antimicrob. Chemother. 57: 1116-1121.

Olofsson SK, Cars O. 2007. Optimizing drug exposure to minimize selection of antibiotic resistance. Clin. Infect. Dis. 45: S129-36.

Patricelli P, Dell' Elce A, Weidmann C, Ramírez E, Presa Rossa C, Aguirre MS, Cadoche L, Formentini E. 2016. Actividad antibacteriana in vitro de ciprofloxacina sobre una cepa autóctona de Escherichia coli: efecto del pH sobre su potencia y efecto de la persistencia bacteriana sobre su modo de acción. FAVE Sección Ciencias Veterinarias 15: 38-47.

Patricelli P, Ramírez E, Presa Rossa C, Dell' Elce A, Formentini E. 2017. Efecto de la persistencia bacteriana sobre la eficacia de enrofloxacina y ciprofloxacina frente a una cepa de Escherichia coli. FAVE Sección Ciencias Veterinarias 16: 30-38.

Rossanigo C. 2013. Enfermedades caprinas de la región centro oeste de la Argentina. Memorias Primer congreso Argentino de Producción Caprina. La rioja, Argentina, Agosto 2013. Pp. 7992.

Schneider M, Vallé M, Woehrlé F, Boisramé B. 2004. Pharmacokinetics of marbofloxacin in lactating cows after repeated intramuscular administrations and pharmacodynamics against mastitis isolated strains. J. Dairy Sci. 87: 202-211.
Sidhu PK, Landoni MF, Aliabadi FS, Lees P. 2010. PK-PD integration and modeling of marbofloxacin in sheep. Res. Vet. Sci. 88: 134-141.

Siroski $\mathrm{P}$, Russi N, Ortega H, Formentini E. 2015. In vitro evaluation of synergistic activity between ciprofloxacin and broad snouted caiman serum against Escherichia coli. Res. Vet. Sci. 98: 98-105.

Tohamy MA, El-Gendy AAM. 2013. Some pharmacokinetic aspects and bioavailability of marbofloxacin in foals. J. Basic. Appl. Sci. 2: 46-50.

Toutain PL, Bousquet-Mélou A, Martinez M. 2007. AUC/MIC: a PK/PD index for antibiotics with a time dimension or simply a dimensionless scoring factor? J. Antimicrob. Chemoth. 60 $1185-1188$

Vallé M, Schneider M, Galland D, Giboin H, Woehrlé F. 2012. Pharmacokinetic and pharmacodynamic testing of marbofloxacin administered as a single injection for the treatment of bovine respiratory disease. J. Vet. Pharmacol. Therap. 35: 519-528.

Waxman S, Rodríguez C, González F, De Vicente ML, San Andrés MI, San Andrés MD. 2001. Pharmacokinetic behavior of marbofloxacin after intravenous and intramuscular administration in adult goats. J. Vet. Pharmacol. Ther. 24: 375 378.

Waxman S, San Andres MD, Gonzalez F, San Andres MI, De Lucas JJ, Rodriguez C. 2004. Age-related changes in the pharmacokinetics of marbofloxacin after intravenous administration in goats. J. Vet. Pharmacol. Therap. 27: 31-35.

Wetzstein HG, 2005. Comparative mutant prevention concentrations of pradofloxacin and other veterinary fluoroquinolones indicate differing potentials in preventing selection of resistance. Antimicrob. Agents. Ch. 49: 4166-4173.

Xu L, Wang H, Yang X, Lu L. 2013. Integrated pharmacokinetics / pharmacodynamics parameters-based dosing guidelines of enrofloxacin in grass carp Ctenopharyngodon idella to minimize selection of drug resistance. BMC Vet. Res. 25: 126.

Yu X-Q, Wilson AGE. 2010. The role of pharmacokinetic and pharmacokinetic / pharmacodynamic modeling in drug discovery and development. Future Med. Chem. 2: 923-928.

Zhang Y, Huo M, Zhou J, Xie S. 2010. PKSolver: An add-in program for pharmacokinetic and pharmacodynamic data analysis in Microsoft Excel. Comput. Methods Programs Biomed. 99: 306-314 